\title{
Effect of Reprocessing and Excipient Characteristics on Ibuprofen Tablet Properties
}

\author{
John Rojas*, Carlos Zuluaga and Andrés Cadavid \\ Department of Pharmacy, School of Pharmaceutical Chemistry, The University of Antioquia, Medellin, Colombia
}

*For correspondence: Email: jrojasca@gmail.com; Tel: 5742195472

Received: 30 May 2014

Revised accepted: 13 May 2015

\begin{abstract}
Purpose: To determine excipient and ibuprofen:excipient mixture sensitivity to reprocessing produced by either direct compression or wet granulation.

Methods: The effect of excipient type, technology and reprocessing on flow, compressibility and compactibility was assessed using and $8 \times 2 \times 2$ factorial design. Design Expert@ v.8.01 software was employed for data analysis. Pure excipients were processed by direct compression, while the ibuprofen:excipient mixtures were processed by wet granulation. Once compacts were produced, they were milled and reprocessed using the same technologies, respectively. Excipient properties such as particle size, porosity and densities were also evaluated.

Results: For most excipients, reprocessing caused a $20-50 \%$ decrease in particle size and $5-80 \%$ reduction in porosity, but increased compactibility (10 - 50\%). Flow decreased (30-50\%) only for highly densified excipients such as calcium carbonate and calcium diphosphate.

Conclusion: Microcrystalline cellulose and sorbitol are the excipients with the best tableting properties when reprocessing is conducted via wet granulation and direct compression platforms, respectively.
\end{abstract}

Keywords: Reprocessing, Excipient, Microcrystalline cellulose, Sorbitol Direct compression, Wet granulation, Ibuprofen

Tropical Journal of Pharmaceutical Research is indexed by Science Citation Index (SciSearch), Scopus, International Pharmaceutical Abstract, Chemical Abstracts, Embase, Index Copernicus, EBSCO, African Index Medicus, JournalSeek, Journal Citation Reports/Science Edition, Directory of Open Access Journals (DOAJ), African Journal Online, Bioline International, Open-J-Gate and Pharmacy Abstracts

\section{INTRODUCTION}

The most common technologies for the production of tablets are direct compression, wet and dry granulation, respectively. However, the choice of a particular technology depends on the physicochemical characteristics of the drug and excipients used. Thus, a successful compression process by direct compression depends on the choice of suitable excipients with excellent compressibility, compactibility and flow properties among others [1]. Direct compression would be the ideal production process because it requires fewer unit operations, consumes less energy, is more economical and causes no physicochemical or microbial stability problems. Nevertheless, there are very few multifunctional direct compressive excipients because not all of them possess adequate tableting and particle properties for compaction [2,3]. For this reason, $\sim 80 \%$ of pharmaceutical production employs the wet granulation technology [4]. When the wet granulation technology is used, the excipient:drug mixture acquires the required flow, compressibility and compactibility to facilitate the manufacturing process, achieve uniform filling of the matrices, regular particle slip and uniform application of pressure to the powder bed [5-7]. The granulation process could also be performed 
by dry compaction. This granulation is desirable for heat or moisture sensitive drugs [8]. The characteristics of the granules produced by direct compression and wet granulation influence compact hardness, disintegration and drug dissolution $[9,10]$. If hydrophobic drugs are used, hydrophilic liquids can be added during wet granulation to wet a powder blend to facilitate tablet disintegration and drug dissolution [11-14] On the other hand, sometimes formulation scientists have to face problems related with manufacture of compacts due to changes in crystallinity, porosity, hygrospicity, particle size which have a deleterious effect on critical manufacturing properties such as flow, compressibility and compactibility of excipients or drug:excipients mixtures. For this reason, Pharmaceutical scientists are forced to correct the defective batches by milling or grinding these compacts and adding an appropriate amount of material having the most suitable properties to correct the intended formulation. In this case, powders improve particle size distribution, density, porosity, flow and compression characteristics and thus, compacts with adequate quality parameters are produced. . The goal of this study is to evaluate the susceptibility of various excipients to recompression employing the direct compression and wet granulation technologies.

\section{EXPERIMENTAL}

\section{Chemicals}

Pregelatinized cassava (lot CS1102) and pregelatinized maize (lot CS1101) were obtained from Corn industries (Cali, Columbia). Starch 1500 (lot IN504089) and ibuprofen (lot QJ0238) were acquired from Colorcon (West Point, PA, USA) and Spectrum Chemicals (New Brunswick, NJ, USA), respectively. Lactose monohydrate (lot 8596021361), Avicel PH101 (lot 6N608C), calcium carbonate (lot 2256KXDS) were obtained from Fonterra (Rosemont, USA), FMC Biopolymers (Philadelphia, PA, USA) and ProtoKimica (Medellin, Columbia), respectively. PVP K-30 (lot 0911106, MW 40,000), sorbitol (lot 024M0118) and calcium diphosphate (lot 024M0118) were purchased from Bell Chem Corp (Longwood, FL, USA).

\section{Powder characterization}

Particle size was determined on a Ro-Tap sieve shaker (RX29, WS Tyler, Mentor, USA) equipped with sieves from 44 to $425 \mu \mathrm{m}$ (Fisher Scientific Co., Pittsburgh, PA) and $50 \mathrm{~g}$ for all samples operated for $15 \mathrm{~min}$. Moisture content was determined in $3 \mathrm{~g}$ of sample on an infrared moisture balance (Scout Pro, OHAUS) at $100{ }^{\circ} \mathrm{C}$ for $15 \mathrm{~min}$. True density and porosity were determined on a Helium pycnometer (AccuPyc II 1340, Micromeritics, USA) with $\sim 1 \mathrm{~g}$ of sample. Bulk density was determined on $20 \mathrm{~g}$ of sample directly measured on a $50 \mathrm{~mL}$ graduated cylinder. Tap density was measured in an AutoTap® density analyzer(AT2, Quantachrome Instruments, Boynton Beach) operated for 1000 cycles. Volume data for each cycle were fitted to the Kawakita compressibility model [8]. Flow rate was determined using $20 \mathrm{~g}$ of sample passed through a glass funnel with a neck diameter of 13 $\mathrm{mm}$ measuring the flow time. This diameter is equivalent to the diameter of the flat-faced punches-and-die set used for the compaction studies. The ratio between mass and the respective time was taken as the flow rate.

\section{Reprocessing susceptibility of pure excipients produced by direct compression}

Direct compression of $\sim 200 \mathrm{~g}$ of a $100 \%$ pure excipient was done on an 8-station tablet machine (Riddhi Pharma Machinery, Gulabnagarahmedabad, India) at $1 \mathrm{rpm}$ using flat-faced punches of $13 \mathrm{~mm}$ diameter to render a $500 \mathrm{mg}$ tablets with a porosity between 10 and $20 \%$. Porosity was determined as in Eq 1.

$$
\varepsilon=1-\left(\mathrm{m} / \rho \mathrm{\rho h} \pi r^{2}\right)
$$

where, $\mathrm{m}, \rho, \mathrm{h}$ and $\mathrm{r}$ correspond to the mass, true density, height and radius of the tablets. These tablets were also analyzed for tensile strength determined from the crushing strength data (UK200, VanKel, Manasquan, USA) as reported previously [9]. Tablets were then passed through an oscillating granulator (Riddhi Pharma Machinery, India) fitted with a \# 20 sieve (840 $\mu \mathrm{m}$ pore size), analyzed for particle size, porosity and densities. These granules were then compressed again under the same conditions.

\section{Reprocessing of excipient:ibuprofen blends $(60: 40)$ produced by wet granulation}

Ibuprofen, which is a poorly compactable drug, was used as a model drug since the desirable dose for a $500 \mathrm{mg}$ compact is $200 \mathrm{mg}$. Thus, 200 $\mathrm{g}$ of ibuprofen:excipient (60:40) blends were prepared and passed freely through a \# 60 sieve (250 $\mu \mathrm{m}$ pore size) to remove aggregates and mixed in a V-blender for $15 \mathrm{~min}$. The powder was then transferred to a ribbon blender (Pharma Machinery Riddhi, India) and $20 \mathrm{~mL}$ of a $10 \%$ PVP solution was added. The wet mass was passed through an oscillating granulator (Riddhi 
Pharma Machinery, India) fitted with \#20 mesh sieve $(840 \mu \mathrm{m}$, pore size).

The granules were dried in a fluidized bed dryer (Indemec, Medellin, Columbia), analyzed for particle size, porosity and densities. These granules were then compressed on a tablet machine (Riddhi Pharma Machinery, India) at 1 rpm using $13 \mathrm{~mm}$ flat-faced punches tooling to render compact of $\sim 500 \mathrm{mg}$ and porosity between 10 and $20 \%$. These tablets were analyzed for tensile strength. Compacts were then passed through an oscillating granulator equipped with a \# 20 mesh, tested again and recompressed under the same conditions.

\section{Statistical analysis}

A full factorial design was employed for the statistical analysis. The validity of this model was tested with the ANOVA analysis, lack of fit test and a new experimental run. The significance level was 0.05 and the statistical analysis was conducted using the Design Expert ${ }^{\circledR}$ software vs. 8.04 (Stat-Easy Inc., Minneapolis, USA).

\section{RESULTS}

The factorial experimental matrix with three factors is shown in Table 1. This matrix is composed of 32 experimental runs, including eight different combinations of excipients processed by direct compression and in blends with ibuprofen processed by wet granulation. Excipient blends with ibuprofen and compressed by direct compression were not attempted since the resulting compacts were so fragile that they broke after ejection and thus,

Table 1: Full factor factorial design matrix for the combination of three factors (technology, excipient, and treatment)

\begin{tabular}{|c|c|c|c|c|c|c|c|c|c|c|}
\hline Lo & $\mathbf{M}$ & TEC & TT & $\begin{array}{c}\text { COM } \\
(\%)\end{array}$ & $\begin{array}{c}\text { TS } \\
(\mathrm{kPa})\end{array}$ & $\begin{array}{l}\text { FR } \\
(g / s)\end{array}$ & $\begin{array}{l}\text { MC } \\
(\%)\end{array}$ & $\begin{array}{c}\text { Pbulk } \\
\left(\mathrm{g} / \mathrm{cm}^{3}\right)\end{array}$ & $\rho_{\text {tap }}\left(\mathrm{g} / \mathrm{cm}^{3}\right)$ & $\begin{array}{c}\rho_{\text {true }} \\
\left(\mathrm{g} / \mathrm{cm}^{3}\right)\end{array}$ \\
\hline 1 & 2 & 1 & 1 & 14.5 & 334.3 & 12.1 & 2.0 & 0.14 & 0.78 & 2.50 \\
\hline 2 & 2 & 2 & 1 & 9.4 & 1693.4 & 21.6 & 1.7 & 0.59 & 0.71 & 2.35 \\
\hline 3 & 8 & 1 & 2 & 12.9 & 90.5 & 24.5 & 4.0 & 0.23 & 0.27 & 1.12 \\
\hline 4 & 1 & 1 & 2 & 17.3 & 424.6 & 65.1 & 2.4 & 1.11 & 1.40 & 3.00 \\
\hline 5 & 3 & 1 & 1 & 15.4 & 81.1 & 37.5 & 1.8 & 0.65 & 0.77 & 2.10 \\
\hline 6 & 1 & 2 & 1 & 1.1 & 692.9 & 24.1 & 4.3 & 0.70 & 0.88 & 1.43 \\
\hline 7 & 1 & 2 & 2 & 49.5 & 424.6 & 44.4 & 0.9 & 0.72 & 1.12 & 1.39 \\
\hline 8 & 7 & 1 & 1 & 7.9 & 50.5 & 10.7 & 5.1 & 0.71 & 0.77 & 1.32 \\
\hline 9 & 6 & 1 & 2 & 20.2 & 36.7 & 31.2 & 3.0 & 0.71 & 0.80 & 1.12 \\
\hline 10 & 6 & 1 & 1 & 11.9 & 96.9 & 14.8 & 4.2 & 0.71 & 0.55 & 1.01 \\
\hline 11 & 4 & 1 & 1 & 18.9 & 83.2 & 72.3 & 1.2 & 1.03 & 1.25 & 3.37 \\
\hline 12 & 5 & 2 & 2 & 12.6 & 1189.3 & 24.9 & 1.2 & 0.58 & 0.67 & 1.36 \\
\hline 13 & 5 & 1 & 2 & 25.2 & 300.5 & 11.0 & 2.9 & 0.5 & 0.66 & 1.25 \\
\hline 14 & 2 & 1 & 2 & 16.7 & 925.4 & 36.8 & 1.3 & 0.14 & 0.80 & 2.51 \\
\hline 15 & 4 & 1 & 2 & 16.2 & 129.1 & 50.6 & 2.6 & 1.05 & 1.25 & 3.28 \\
\hline 16 & 4 & 2 & 2 & 8.5 & 59.1 & 25.4 & 2.2 & 0.67 & 0.74 & 1.52 \\
\hline 17 & 1 & 1 & 1 & 9.7 & 719.4 & 68.7 & 2.0 & 1.11 & 1.27 & 2.78 \\
\hline 18 & 8 & 1 & 1 & 9.7 & 47.4 & 17.4 & 4.7 & 0.59 & 0.65 & 1.12 \\
\hline 19 & 3 & 1 & 2 & 70.8 & 49.4 & 24.8 & 2.1 & 0.67 & 0.83 & 1.93 \\
\hline 20 & 4 & 2 & 1 & 10.6 & 68.2 & 14.9 & 2.5 & 0.67 & 1.63 & 1.63 \\
\hline 21 & 5 & 2 & 1 & 21.9 & 1356.7 & 21.5 & 2.4 & 0.45 & 0.57 & 1.39 \\
\hline 22 & 5 & 1 & 1 & 21.9 & 473.3 & 16.0 & 2.0 & 0.45 & 0.57 & 1.18 \\
\hline 23 & 3 & 2 & 2 & 9.7 & 1348.5 & 31.1 & 1.2 & 0.58 & 0.67 & 1.35 \\
\hline 24 & 8 & 2 & 2 & 11.6 & 5782.9 & 30.4 & 1.0 & 0.52 & 0.59 & 1.33 \\
\hline 25 & 2 & 2 & 2 & 9.3 & 1510.4 & 29.7 & 2.8 & 0.59 & 0.67 & 2.24 \\
\hline 26 & 6 & 2 & 2 & 11.7 & 1950.9 & 24.9 & 4.4 & 0.56 & 0.65 & 1.40 \\
\hline 27 & 7 & 1 & 2 & 12.4 & 48.9 & 6.5 & 5.3 & 0.71 & 0.82 & 1.35 \\
\hline 28 & 6 & 2 & 1 & 9.7 & 1181.3 & 27.1 & 3.3 & 0.50 & 0.57 & 1.32 \\
\hline 29 & 7 & 2 & 1 & 5.5 & 793.0 & 14.9 & 4.3 & 0.52 & 0.57 & 1.31 \\
\hline 30 & 7 & 2 & 2 & 7.9 & 390.4 & 20.5 & 4.1 & 0.56 & 0.65 & 1.26 \\
\hline 31 & 3 & 2 & 1 & 8.7 & 50.1 & 24.8 & 4.6 & 0.53 & 0.57 & 1.31 \\
\hline 32 & 8 & 2 & 1 & 12.4 & 5781 & 24.3 & 1.0 & 0.55 & 1.25 & 1.31 \\
\hline
\end{tabular}

M, material (1. Calcium carbonate; 2. sorbitol, 3. Cassava starch; 4. Calcium diphosphate; 5. Microcrystalline cellulose (Avicel ${ }^{\circledR}$ PH101); 6. Pregelatinized starch; 7. Starch1500 ${ }^{\circledR} ;$ 8. Lactose monohydrate); TEC, technology (1. Direct compression; 2. Wet granulation); TT, treatment (1. Processing; 2. Reprocessing); COM, compressibility; TS, Tensile strength; FR, flow rate; MC, moisture content 
were not included in the experimental matrix. The selected most critical responses for the tableting process were compressibility, compactibility and flow rate. Since all materials were dried in an oven for $3 \mathrm{~h}$ at $105^{\circ} \mathrm{C}$, the moisture content was controlled below $5.3 \%$ and hence, this factor was not included in the experimental design. Further, the contribution of the effects of the excipient type, technology and reprocessing on densification and packing ability were reflected on changes in powder porosity.

Figure 1 shows the variation of particle size and porosity with processing and the technology used. When materials were direct compressed and reprocessed there was an increase in particle size of cassava starch and pregelatinized starch, whereas the particle size of lactose monohydrate decreased. Conversely, when granules were produced by wet granulation and reprocessed no change in particle size was observed, except for calcium carbonate, sorbitol and lactose monohydrate. On the other hand, when drug:excipient granules were subjected to recompression there was a decrease in porosity, except for lactose in which it increased slightly. Conversely, for the pure excipients recompression led to an increase in porosity, except for starch 1500 where porosity decreased slightly. The latter always exhibited a decrease in particle size independent of the technology used.
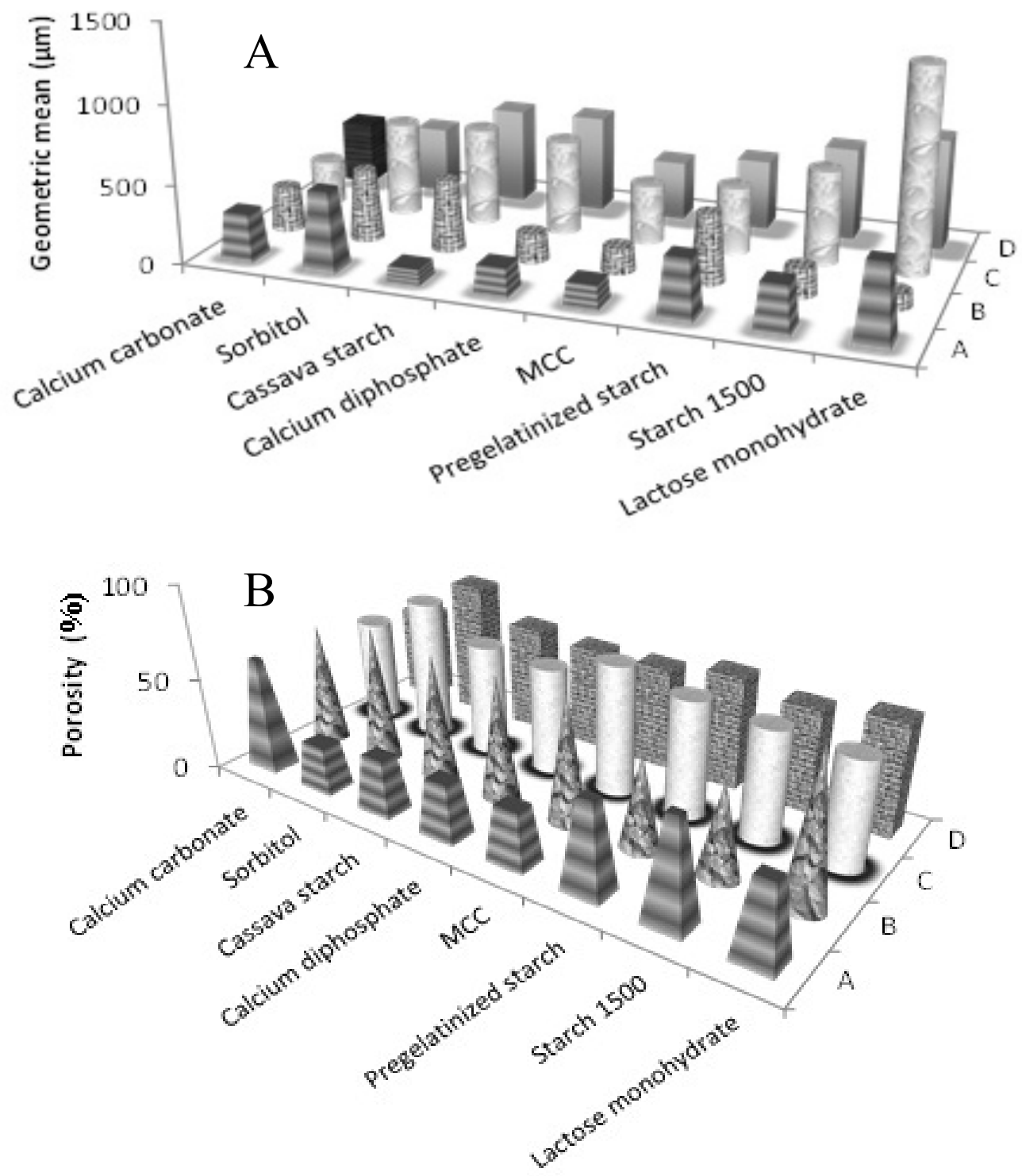

Figure 1: Effect of particle size (A) and porosity $(B)$ on processing and reprocessing for pure excipients and in mixtures with ibuprofen 
Table 2 shows the analysis of variance for the responses studied. The technology used (direct compression or wet granulation) and treatment (processing or reprocessing) were considered as significant for compressibility and flow rate. On the contrary, compactibility was affected by all three factors. In all cases, the coefficient of determination was greater than 0.7038 indicating a good fit of the data to the factorial model, being the highest for compactibility (0.9750).

The models obtained for the three selected properties are:

- $\operatorname{Ln}\left(\right.$ Compressibility) $=2.5-7.759 \times 10^{-3} * A[1]-0.037$ * $A[2]+0.046$ * $A[3]+0.012$ * $A[4]+0.037$ * $A[5]+0.011$ * $A[6]-5.348 \times 10^{-3} * A[7]-0.25 * B+0.22 * C-0.042$ * $\mathrm{A}[1] \mathrm{C}+0.045$ * $\mathrm{A}[2] \mathrm{C}-0.074$ * $\mathrm{A}[3] \mathrm{C}+2.362 \times 10^{-3}$ * $A[4] C-0.049$ * $A[5] C+0.024$ * $A[6] C-1.960 \times 10^{-3}$ * $A[7] C$

- Compactibility $=880.1+86.9 * A[1]+105.4 * A[2]+174$

* $A[3]+16.9$ * $A[4]+171.0$ * $A[5]+9.6$ * $A[6]$ * 2.6 * $A[7]+636.9$ * $B+123.4$ * $A[1] B+91.7$ * $A[2] B+189.7$ * $A[3] B+17.4$ * $A[4] B+126$ * $A[5] B+24.8$ * $A[6] B-0.82$ * $\mathrm{A}[7] \mathrm{B}$

- Flow rate $=28.3-1.7$ * $A[1]+0.61$ * $A[2]-0.26$ * $A[3]+0.64$ * $A[4]-1.07 * A[5]+0.28 * A[6]+0.21 * A[7]-$ 2.98 * $B+1.14$ * $A[1] B-0.045 * A[2] B+0.21 * A[3] B-0.49$ ${ }^{*} A[4] B+1.54$ * $A[5] B+0.15$ * $A[6] B-0.24$ * $A[7] B$

\section{DISCUSSION}

The particle size of the lactose was significantly reduced after reprocessing by either direct compression or wet granulation. This is explained by its fragile character upon consolidation, since large particles once compressed fragment down into smaller particles increasing the surface area available for compaction and hence, its compactibility increased upon reprocessing. Moreover, most of the pure excipients processed by direct compression had an increase in porosity after reprocessing. This implies an increase in the number of spaces between fine particles, increase of specific surface area and reduction of powder density keeping a large amount of air within particle micropores causing a decrease in flowability. On the contrary, when wet granulation took place porosity decreased slightly due to the formation of larger regular granules along with a low percentage of fines $(<5 \%)$.

However, this behavior was only significant for microcrystalline cellulose. Therefore, granules were able to settle more readily on the die bed improving their flow.

Reprocessing improved the compressibility of calcium carbonate and cassava starch. However, the compressibility of their granules in mixtures

Table 2: ANOVA data for compressibility, compactibility and flow rate

\begin{tabular}{|c|c|c|c|c|c|}
\hline Compressibility & $\begin{array}{l}\text { Sum of } \\
\text { square } \\
\text { (SS) }\end{array}$ & $\begin{array}{l}\text { Degrees } \\
\text { freedom } \\
\text { (DF) }\end{array}$ & $\begin{array}{l}\text { Mean } \\
\text { square } \\
\text { (MS) }\end{array}$ & F-value & P-value \\
\hline \multicolumn{6}{|l|}{ Source of variation } \\
\hline Model & 10.2 & 16 & 0.6 & 2.2 & 0.064 \\
\hline Material (A) & 2.3 & 7 & 0.3 & 1.2 & 0.382 \\
\hline Technology (B ) & 2.0 & 1 & 2.0 & 7.1 & 0.018 \\
\hline Treatment (C) & 1.6 & 1 & 1.6 & 5.5 & 0.033 \\
\hline$A C$ & 4.3 & 7 & 0.6 & 2.1 & 0.103 \\
\hline Residual & 4.3 & 15 & 0.3 & & \\
\hline Total corrected & 14.5 & 31 & & r2 & 0.7038 \\
\hline \multicolumn{6}{|l|}{ Compactibility } \\
\hline Model & $6.0 \times 10^{\prime}$ & 15 & $4.0 \times 10^{6}$ & 41.6 & $<0.0001$ \\
\hline Material $(A)$ & $2.2 \times 10^{\prime}$ & 7 & $3.2 \times 10^{6}$ & 33.2 & $<0.0001$ \\
\hline Technology (B) & $1.3 \times 10^{\prime}$ & 1 & $1.3 \times 10^{\prime}$ & 136.25 & $<0.0001$ \\
\hline$A B$ & $2.4 \times 10^{\prime}$ & 7 & $3.5 \times 10^{6}$ & 36.5 & $<0.0001$ \\
\hline Residual & $1.5 \times 10^{6}$ & 16 & 95272.9 & & \\
\hline Total corrected & $6.1 \times 10^{\prime}$ & 31 & & $r^{2}$ & 0.9750 \\
\hline \multicolumn{6}{|l|}{ Flow rate } \\
\hline Model & 7102.4 & 15 & 473.5 & 6.5 & 0.0003 \\
\hline Material $(A)$ & 4098.2 & 7 & 585.5 & 8.0 & 0.0003 \\
\hline Technology (B) & 284.5 & 1 & 284.5 & 3.9 & 0.066 \\
\hline$A B$ & 2719.6 & 7 & 388.5 & 5.3 & 0.003 \\
\hline Residual & 1166.9 & 16 & 72.9 & & \\
\hline Total corrected & 8269.2 & 31 & & $r^{2}$ & 0.8589 \\
\hline
\end{tabular}


with ibuprofen decreased. Except for calcium diphosphate, the compactibility of the granules was better than that of the powders. This effect was most salient for lactose. Furthermore, the wet granulation process improved flow for Starch1500® and Avicel, whereas flow decreased for calcium carbonate and calcium phosphate using the same technology.

In general, the increase in porosity in the powered excipients was more pronounced than the increase in porosity of the granules. This indicates that opposite to powders, granules formed after grinding and subsequent reprocessing either maintained or increased in
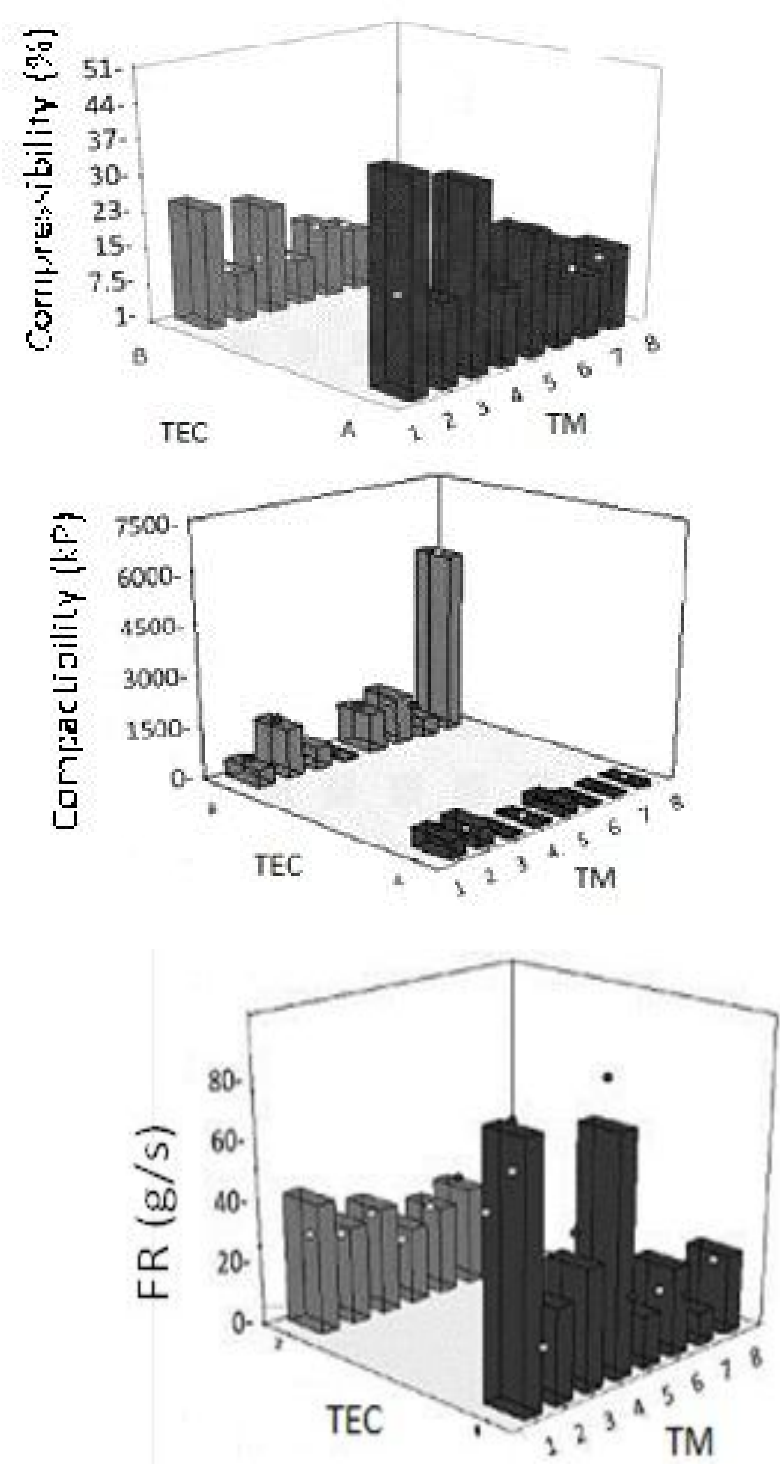

size preventing densification or volume reduction. The above results proved that the volume reduction ability or compressibility of the excipients decreased during the wet granulation process due to the formation of large and regular particles with low porosity and a greater packing capacity in the die bed (Fig 2). Thus, the granules do not have enough space for a further volume reduction. This behavior was not affected by reprocessing, indicating that when tablets are reprocessed they broke and formed granules or aggregates as initially observed. Except for calcium diphosphate, compactibility was higher for compacts produced by wet granulation rather than direct compression (Figure 2). This is
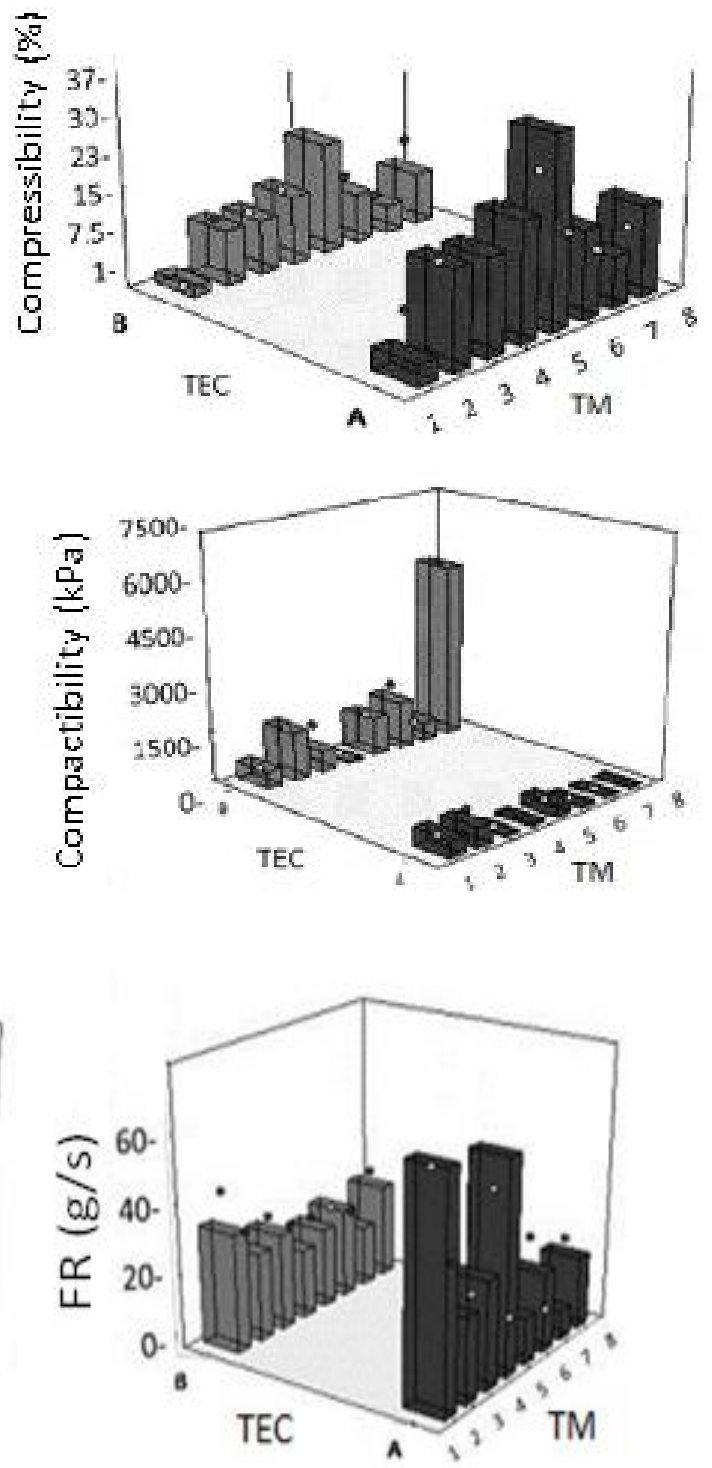

Figure 2: Excipient functionality. TEC, Technology, TM, type of material, 1. Change of compressibility with processing: (A) Direct compression, (B) wet granulation (excipient:ibuprofen mixtures). 2. Change of compressibility with reprocessing: (A) Direct compression (B) wet granulation. 3. Change of compactibility with processing: $(A)$ Direct compression $(B)$ wet granulation. 4. Change of compactibility with reprocessing: $(A)$ Direct compression (B) wet granulation. 5. Change of flow rate with processing: (A) Direct compression (B) wet granulation. 6. Change of flow rate with reprocessing: $(A)$ Direct compression (B) wet granulation. 1, Calcium carbonate; 2, Sorbitol, 3. Cassava starch; 4, Calcium diphosphate; 5, microcrystalline cellulose; 6, pregelatinized starch; 7, Starch1500; and 8. Lactose monohydrate 
Table 3: Comparison between theoretical and experimental values of excipient properties

\begin{tabular}{|c|c|c|c|c|c|c|c|c|c|}
\hline \multirow[b]{2}{*}{ Run } & \multirow{2}{*}{$\begin{array}{l}\text { Factor } \\
\text { Material }\end{array}$} & \multirow[b]{2}{*}{ Technology } & \multirow[b]{2}{*}{ Treatment } & \multicolumn{3}{|c|}{ Theoretical } & \multicolumn{3}{|c|}{ Experimental } \\
\hline & & & & $\begin{array}{l}\text { COM } \\
(\%)\end{array}$ & $\begin{array}{l}\text { TS } \\
(\mathrm{kPa})\end{array}$ & $\begin{array}{l}\text { FR } \\
(\mathrm{g} / \mathrm{s})\end{array}$ & $\begin{array}{l}\text { COM } \\
(\%)\end{array}$ & $\begin{array}{l}\text { TS } \\
(\mathrm{kPa})\end{array}$ & $\begin{array}{l}\text { FR } \\
(g / s)\end{array}$ \\
\hline$A$ & $\begin{array}{l}\text { Microcrystalline } \\
\text { cellulose }\end{array}$ & $\begin{array}{l}\text { Wet } \\
\text { granulation }\end{array}$ & Processing & 7.0 & 273.0 & 3.2 & 1.9 & 356.7 & 21.5 \\
\hline B & Sorbitol & $\begin{array}{l}\text { Direct } \\
\text { compression }\end{array}$ & Reprocessing & 6.0 & 629.9 & 4.4 & 6.7 & 25.4 & 36.8 \\
\hline
\end{tabular}

COM, compressibility, TS, tensile strength, FR, Flow rate

explained by the increase in plasticity of the materials due to the contribution of the wet binder (PVP-k30) compensating the brittle behavior of ibuprofen. As a result, compacts with a high tensile strength are obtained. In the case of lactose, the ductile behavior was so high that their tablets deformed before breaking producing compacts of very high tensile strength. Therefore, PVP-k30 counteracted the combined brittle behavior of lactose and ibuprofen altogether. It is plausible that the presence of water in the hydrate form also contributed to ductility. However, this was not reflected in the resulting moisture content which was $~ 1.0 \%$ due to the presence of bound water (Table 1).

In general, excipients both treated by direct compression or wet granulation and further recompressed showed a decrease in compactibility except for sorbitol, microcrystalline cellulose, lactose monohydrate and pregelatinized starch. This indicates that particle cohesiveness remained unaffected by recompression and thus, these excipients are also expected to withstand the process of dry granulation by double compression.

Moreover, the excipient flow was virtually unaffected except for inorganic excipients such as calcium carbonate and calcium diphosphate (Figure 2). This was ascribed to their high bulk and tap densities $\left(1.1 \mathrm{~g} / \mathrm{cm}^{3}\right.$ and $1.5 \mathrm{~g} / \mathrm{cm}^{3}$, respectively), which decreased (0.7 and 1.13 $\mathrm{g} / \mathrm{cm}^{3}$, respectively) after reprocessing independent of the technology used.

The combination of factors from the models which predict a compressibility between 15-30\%, tensile strength from 500 to $5000 \mathrm{kPa}$ and flow rate between 15-30 $\mathrm{g} / \mathrm{s}$ determined microcrystalline cellulose and sorbitol as the excipients with the best properties for use for wet granulation and direct compression, respectively and eventually can withstand reprocessing if needed (Table 3). All other excipients did not match the range for the optimal performance of these previously described properties. The proximity of the experimental values to the theoretical models explains the validity of the models.

\section{CONCLUSION}

Based on the desired range for compressibility, tensile strength and flow rate microcrystalline cellulose resulted as the best excipient for the production of ibuprofen compacts by wet granulation, whereas sorbitol was the best of its kind for direct compression if reprocessing is eventually needed. On the other hand, reprocessing increased excipient porosity, while it remained virtually unchanged for ibuprofen: excipient treated by wet granulation followed by reprocessing.

\section{ACKNOWLEDGEMENT}

We greatly thank the committee for the development of research (CODI) and its sustainability strategy (2013-2014) for their financial support.

\section{REFERENCES}

1. Bansal AK. Improved excipients by solid state manipulation. Ind Pharm 2003; 31: 9-12.

2. Joshi $A A$, Duriez $X$. Added functionality excipients: An answer to challenging formulations. Pharmaceutical technology, excipients \& solid dosage forms. 2004; 12-19.

3. Shangraw $R$, Demarest $D$. A survey of current industrial practices in the formulation and manufacture of tablets and capsules. Pharm Technol 1993; 17: 3233.

4. Bolhuis GK, Armstrong AN. Excipients for direct compaction-an update. Pharm Dev Technol 2006; 11: 111-124

5. Gohel MC, Jogani PD. A review of coprocessed directly compressible excipients, J Pharm Pharmaceut Sci 2005; 8: 76-93.

6. Shangraw RF. Direct Compression Tableting, Encyclopedia of Pharmaceutical Technology. 2nd. Vol 4. New York: Marcel Dekker; 1988; pp 85-160. 
7. Chang D, Chang R. Review of current issues in pharmaceutical excipients. Pharm Technol 2007; 31: 56.

8. Kawakita K, Ludde KH. Some considerations on powder compression equations. Powder Technol 1971; 4: 6168.

9. Akseli I, Cuitiño AM, lyer S, Lee HP. A quantitative correlation of the effect of density distributions in roller-compacted ribbons on the mechanical properties of tablets using ultrasonics and $X$-ray tomography. AAPS PharmSciTech 2011; 12: 834853.

10. Chen J, Hussain MA, Pang J, Wu L. Dry blending process scale-up for a very low dose drug candidate. AAPS PharmSciTech 2001; 1: 5-9.

11. Carvajal MT, Feng $T$, Feng $W$, Pinal $R$, Wassgren $C$. Investigation of the variability of NIR in-line monitoring of roller compaction process by using fast
Fourier transform (FFT) analysis. AAPS

PharmSciTech 2008; 9: 419-424.

12. González Ortega G, Petrovick PR, Lira Soares $L A$, Schmidt PC. Dry granulation and compression of spray-dried plant extracts. AAPS PharmSciTech. 2005; 6: 359-366.

13. Alvarez-Nunez FA, Chang CK, Magnusson L, Rinella JV, Sueda K. Roller compaction, granulation and capsule product dissolution of drug formulations containing a lactose or mannitol filler, starch, and talc. AAPS PharmSciTech 2008; 9: 597-604.

14. Endale A, Gebre-Mariam T, Schmidt PC. Granulation by roller compaction and enteric coated tablet formulation of the extract of the seeds of glinus lotoides loaded on AeroperIB 300 Pharma. AAPS PharmSciTech 2008; 9: 31-38.

15. Fell JT, Newton JM. The tensile strength of lactose tablets. J Pharm Pharmacol 1968; 20: 657-758. 